\title{
What Should Graduating Geological Engineers Know and Be Able to Do? Redesigning Curricula on the Basis of Graduate Attributes
}

\author{
V.H. Remenda, Ph.D., P.Eng. \\ Assoc. Professor, Dept Geological Sciences and Geological Engineering \\ Queen's University \\ Remenda@geol.queensu.ca
}

\begin{abstract}
Curriculum revision is often a process of evaluating existing courses and working out slight modifications in order to satisfy external agencies and internal teaching rosters. In 2008, the Geological Engineering Curriculum Committee (GECC) at Queen's University, a team of eight faculty members, began by concept mapping what skills, knowledge and attitudes are required for geological engineering students to begin their careers. The motivation of curricular redesign was the desire to reduce the program from four options to one flexible program. Additional pressures included the loss of one faculty member and anticipated financial constraints within the university. From the original concept mapping several key diagrams of graduate attributes were created to guide the revision process. The resulting program, with revised courses, has several advantages: it is the result of a shared vision, it intentionally develops the technical knowledge, and design and professional skills from second year to fourth through a common core, it allows students flexibility in stream and technical electives, and satisfies the current CEAB Accreditation Units. In addition, by starting with the knowledge, skills and attitudes that we view as essential to practicing geological engineer we are well positioned to transition to the planned CEAB graduate attribute assessment.
\end{abstract}

\section{Introduction}

Geological engineering curricula at Queen's University in Kingston Ontario have undergone many changes in response to enrolment cycles, faculty expertise, financial pressures and accreditation expectations. By the mid-2000's, geological engineering students enrolled in one of the four options (G3 Mineral and Energy Exploration, G5 Geotechnique, G5 GeoEnvironmental, and G7,
Geophysics) following the first year. The options had a common core rich in field and laboratory experiences designed and implemented starting in 1997-1998 [1] and refined in subsequent years. Each option had enrolments of 4 to 15 students with a total student complement in any one year of about 30 students. In the summer of 2008 the Geological Engineering Curriculum Committee (GECC) undertook a major redesign of years two to four. The motivation for the curricular redesign was the desire to reduce the program from four options to one flexible program, and to respond to pressures including the loss of one faculty member and anticipated financial constraints within the university. The curriculum revision was achieved by creating a shared vision of the attributes of a graduating geological engineering student via concept mapping.

\section{Graduate Attributes}

In Ontario, the Council of Academic Vice-Presidents (OCAV) developed a set of six generic graduate attributes (named UUDLES, for university undergraduate degree level expectations) [2]. These graduate attributes (which I will call GA) have now been incorporated into the reporting structures for undergraduate degree programs in the province. Similarly, the Canadian Engineering Accreditation Board (CEAB) requires that $12 \mathrm{GA}$ be assessed by engineering schools seeking accreditation [3]. Queen's Faculty of Engineering and Applied Science has developed and assessed first year attributes in the 2009/2010 academic year and will begin assessment of graduate attributes in the Fall of 2010.

Developing GA and creating strategies to implement and assess GA, has been identified as beneficial to universities and the governments that fun them [4] [5] Basic attributes have been identified, more or less universally, as acquisition of disciplinary knowledge; facility with the use of and incorporation of that knowledge; capacity for ethical and socially responsible actions; and skills for employment and 
life-long learning[5]. That the university as a social good is embedded in the mission and values of many institutions of higher education, however, the move to GA is almost always is rooted in economic and political actions of governments [5]. Perhaps the resistance to adopting GA noted by [6] is because they are often imposed by outside agencies, such as governments or accreditation boards such as the $\mathrm{CEAB}$, or by university administrators. Despite the resistance from some corners, there is evidence that there are benefits to developing curricula formulated around shared, generic GA[4].

\section{Concept Mapping of GA}

Concept mapping for constructing knowledge and linkages among knowledge areas was pioneered by Novak [7] and popularized by Buzan [8]. In general, concept mapping involves using a chalkboard, white board, large sheet of paper or software on which is placed a central theme such as "technical knowledge needed to undertake an engineering project" or "what needs to be done for Friday night's dinner party". Participants then brainstorm the categories of activities/knowledge areas that are needed to complete the project at hand. Linkages are identified among the categories, for example, modeling of a certain process depends on field data, and the collection of field data may be designed in order to fulfill the modeling task. A properly constructed concept map shows activities that are linked to each other. Each activity or knowledge area is then broken down into smaller steps or sub-steps depending on the complexity and size of the project being planned. The resulting map can be used as the basis for Critical Path modeling, Gantt Charts and Pert charts if desired.

\section{Developing a Shared Vision of GA}

We began with the goal of revising the four, three-year options. The effort was lead by the then Undergraduate Chair of Geological Engineering (now department head) Dr. D. Jean Hutchinson, P.Eng. We began with a concept mapping exercise that allowed us to explore what the desirable attributes of a student graduating from our program. (Interestingly, at the time we began this revision were no aware that various agencies were introducing GA.) What should our students know? What should they be able to do? What kind of attitudes do we want them to leave with? Figure 1 illustrates the final concept map that was developed by GECC and encapsulated by my colleague Dr. Mark Diederichs, P.Eng now Chair of the Undergraduate Curriculum Committee. Concept mapping allowed us to brainstorm the specific knowledge that a Queen's Geological Engineer should have at graduation and included topics such as tectonics, mineral paragenesis, earth materials (rock, soil, water), geohazards, geochemistry, and geomechnanics. All of the members of GECC contributed to the final concept map thus ensuring that it represented a shared vision. This is particularly important in curriculum revision because members of the committee would then be tasked with revising courses and creating assessment tools aligned with the new curriculum. (It should be mentioned that some content-based courses are taken by both science and engineering students, whereas all of the design and process-based courses are given exclusively to engineering students)

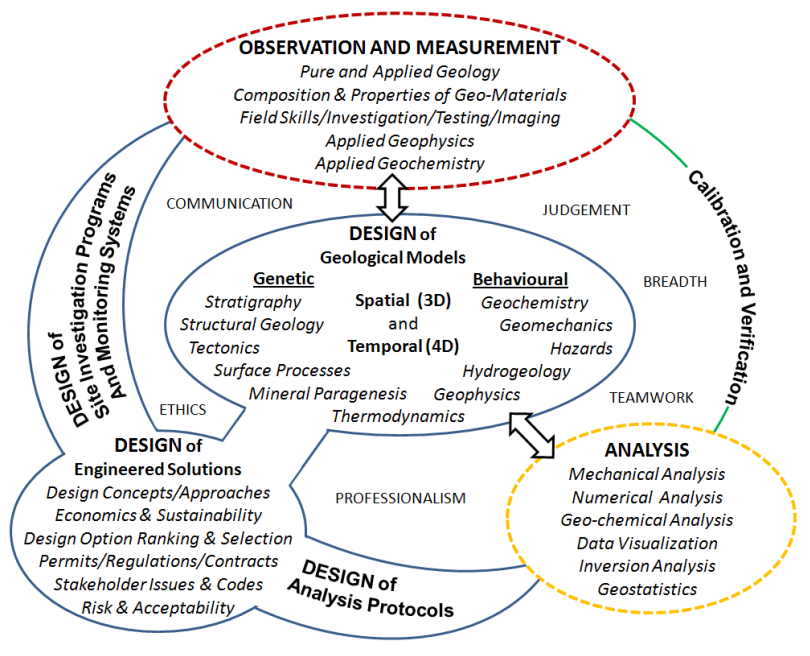

Figure 1: The Concept Map developed by GECC. Note that GA in the form of knowledge, skills and attitudes are enumerated and linked.

\section{Evaluation against OCAV and CEAB GA}

An analysis of Figure 1 against GA [2] [3] show that these knowledge areas are comparable to OCAV's first GA, depth and breadth of knowledge and CEAB's first GA, knowledge base in engineering. The key skills identified by GECC were design of site investigation programs and monitoring systems, design of analysis protocols, and design of engineered solutions. The format of the concept map (Figure 1) illustrates how the first two design steps flow into the design of engineered solutions and recognizes that most geological engineering undertakings are subject 
to government regulation. Geological engineers must be aware that the design of the system of field and lab observation and measurement may have a profound impact on the resulting data and interpretation. In addition, understanding the genesis of geometry and characteristics of earth materials, including the spatial and temporal, are critical to design and to predicting outcomes. Failures are almost always associated with insufficient knowledge of earth system processes and insufficient investigation. In addition, team work is identified as a skill that requires development within the curriculum.

These skills compare to OCAV's $2^{\text {nd }}$ and $3^{\text {rd }} \mathrm{GA}$ (knowledge of methodologies and application of knowledge) and the CEAB's $2^{\text {nd }}$ to $5^{\text {th }}$, and $11^{\text {th }} \mathrm{GA}$ (problem analysis, investigation, design, use of engineering tools and economics and project management). Although we do not explicitly state that project management is a key GA for geological engineers, it is implied. The design of site investigation programs require a phased approach that begins with a desk-top study of existing information used to develop the initial conceptualization that is subsequently tested and refined in the phased field and laboratory investigation, and the results are used to create appropriate design solutions.

What attitudes are important? GECC identified professionalism, including ethics, judgment, risk, and acceptability as key attributes. In addition, stakeholder issues and environmental sustainability were highlighted thus recognizing that most geological engineering projects affect people and the environment. The attributes correspond to OCAV's $6^{\text {th }} \mathrm{GA}$ (autonomy and professional capacity) and CEAB's $8^{\text {th }}, 9^{\text {th }}$ and $10^{\text {th }} \mathrm{GA}$ (professionalism, impact of engineering on society and the environment, and ethics and equity).

\section{From GA to Curriculum Map}

The next step was to evaluate the existing curriculum in light of the concept map of knowledge, skills and attitudes. We identified strengths in the existing curriculum such as a strong common core, a systematic building of discipline-specific knowledge from $2^{\text {nd }}$ to $4^{\text {th }}$ years, and a very rich field program. Another strength of our program was the emphasis on open-ended design at the end of $2^{\text {nd }}$ year (GEOL 310 Geological Engineering Field School) where students design a detail site investigation in support of a large scale geological engineering project such as a road or mine and in $4^{\text {th }}$ year (GEOL 445 Site Investigation and Case Histories) and the two design courses (GEOL 446 and 447 Engineering Design I and II).
Of the several weaknesses or inconsistencies that emerged one was that the third year lacked a design opportunity equivalent to those at the $2^{\text {nd }}$ and $4^{\text {th }}$ years. In addition, $\mathrm{s}$ ome areas of core knowledge (e.g. geomechanics, geohydrology, and advanced information related to mineral and energy exploration) were not present in all the four options above the second year. Finally, we identified that we could not deliver the number of courses in the four options with the current resources, especially three senior field courses.

The final curriculum design, shown at [10], indicates the progression of knowledge, skills and attitudes in a flexible program that uses stream and technical electives for specialization. Emphasis changes from content-based courses in $2^{\text {nd }}$ year to process-oriented course in $4^{\text {th }}$ year. Stream electives are a restricted group of courses that have been identified as offering specialized engineering knowledge and design. The technical elective list includes the stream elective list (i.e. a student choosing two of four possible stream electives may take the remaining courses as technical electives if he or she wishes) in addition to courses with technical but not necessarily engineering content which may be offered by non-engineer members of the department or cognate departments such as geography.

To rectify the lack of design opportunities in the $3^{\text {rd }}$ year, the core course GEOL 445 Site Investigation and Case Histories was moved from the fall of $4^{\text {th }}$ year to the winter of $3^{\text {rd }}$ year and renamed GEOL 345 Site Investigation and Geological Engineering Design. It will be modified substantially to include teaching of design methods and an open-ended, team design project as a precursor to the design pair in $4^{\text {th }}$ year. To ensure that all geological engineering students have the breadth of disciplinary knowledge identified in the concept mapping, courses such GEOL 362, formerly Petrology Applied to Ore Deposits, now Resource Engineering, GEOL 343 Hydrogeology, and GEOL 413 Geomechanics and Rock Engineering were moved into the core. Finally three $4^{\text {th }}$ year field courses were collapsed to one compulsory fall term course that will cover elements of the four and will provide an element of design. The final changes will be implemented in 2010-2011 and 2011-12 school years.

\section{Next Steps}

The analysis of the new program introduced to students entering Geological Engineering in the Fall of 2009, against OCAV and CEAB GA has shown a remarkable consistency within only a very few gaps. Although life long learning (or inquiry learning) is incorporated at all levels of the program, it is not stated explicitly in the concept map. Secondly, 
understanding the limits of knowledge, identified by OCAV, of particular importance to engineers making critical decisions, is not present. Although it is implicit in the redesigned program neither Figure 1 or 2 illustrate where the GA and occur, and how they will be assessed.

\section{Conclusions}

Concept mapping graduate attributes for a new program in geological engineering resulted in a shared vision and a robust new curriculum. An analysis of the program-specific GA against those developed by OCAV and CEAB identified some areas that we need to make explicit, namely life long learning and understanding the limits of knowledge. Considerable work on how we will assess our program and faculty GA remains, but we have made a good start.

\section{References}

[1] Lee, J.K.W., J.A. Hanes, V.H. Remenda. New curriculum reforms in a geological engineering program. J. Engineering Education. 2001. pp 721-728.

[2] Ontario Council of Academic Vice-Presidents. University Undergraduate Degree Level Expectations. (website accessed May 16, 2010) 2005.

[3] Canadian Engineering Accreditation Board. www.engineerscanada.ca/e/files/report_ceab_08.pdf [4] Barrie, S.C. Understanding what we mean by the generic attributes of graduates. Higher Education. 2006. pp 215-241.

[5] Jones, J. Generic attributes: an agenda for reform or control? Changing Identities: Proceedings of the Language and Academic Skills Conference, University of Wollongong. http://learning.uow.edu.au/LAS2001/selected/jones 2 . pdf accessed May 17, 2010.

[6] Legget, M., A. Kinnear, M. Boyce, and I. Bennet. Student and staff perceptions of the importance of generic skills in science. Higher Education Research and Development. 2004. pp 295-312.

[7] Novak, J. D. and A. J. Cañas, The Theory Underlying Concept Maps and How to Construct and Use Them, Technical Report IHMC CmapTools 2006-01 Rev 01-2008, Florida Institute for Human and Machine Cognition, 2008, available at: http://cmap.ihmc.us/Publications/ ResearchPapers/TheoryUnderlyingConceptMaps.pdf (accessed May 16, 2010).

[8] Buzan, T. 2006. Mind Map Book. Educational Publishers LLP Edinburgh, UK. [9] http://geol.queensu.ca/eng web/department/docume nts/GEOL 2012.pdf accessed May 17, 2010. 